\title{
Polymorphisms in genes MTHFR, MTR and MTRR are not risk factors for cleft lip/palate in South Brazil
}

A.P.C. Brandalize ${ }^{1,2}$, E. Bandinelli ${ }^{1}$, J.B. Borba ${ }^{1}$, T.M. Félix ${ }^{3}$, I. Roisenberg ${ }^{1,2}$ and L. Schüler-Faccini ${ }^{1,2,3}$
${ }^{1}$ Departamento de Genética, ${ }^{2}$ Programa de Pós-Graduação em Genética e Biologia Molecular, Universidade Federal do Rio Grande do Sul, Porto Alegre, RS, Brasil ${ }^{3}$ Serviço de Genética Médica, Hospital de Clínicas de Porto Alegre, Porto Alegre, RS, Brasil

\section{Correspondence}

L. Schüler-Faccini

Departamento de Genética

Instituto de Biociências, UFRGS

Caixa Postal 15031

91501-970 Porto Alegre, RS

Brasil

Fax: +51-3316-7311

E-mail: lavinia.faccini@ufrgs.br

Research supported by $\mathrm{CNPq}$ and CAPES.

Received May 30, 2006 Accepted March 26, 2007 ... . . . . . . . . . . . .

\begin{abstract}
Non-syndromic cleft lip and palate (CL/P) occurs due to interaction between genetic and environmental factors. Abnormalities in homocysteine metabolism may play a role in its etiology due to polymorphisms in genes involved in this pathway. Because of the involvement of MTHFR, MTR and MTRR genes with folate metabolism and the evidence that maternal use of folic acid in early pregnancy reduces the risk for $\mathrm{CL} / \mathrm{P}$, we evaluated the influence of their polymorphisms on the etiology of CL/P through a case-control study. The analyses involved 114 non-syndromic phenotypically white children with clefts (case) and 110 mothers, and 100 non-affected (control) children and their mothers. The polymorphisms $677 \mathrm{C}>\mathrm{T}$ of MTHFR, 2756A $>\mathrm{G}$ of MTR, and $66 \mathrm{~A}>\mathrm{G}$ of MTRR genes were analyzed by PCR-RFLP. Allelic frequencies did not differ from other studies conducted on white populations for MTHFR 677T allele (0.35) and for MTR 2756G allele (0.17), but MTRR 66G allele frequency (0.35) was lower than observed elsewhere. The genotypic distribution of the $677 \mathrm{C}>\mathrm{T}$ polymorphisms under study did not show significant differences between CL/P patients, their mothers and controls. These results suggest that the alterations of folate metabolism related to these polymorphisms are not involved in clefting in the population under study.
\end{abstract}

\section{Introduction}

Craniofacial anomalies, particularly cleft lip/palate (CL/P), are among the most common birth defects. They affect approximately 1 in 700 births, a frequency which may differ according to the geographical region and socio-economic level. Collectively, the CL/ $\mathrm{P}$ have a great clinical impact, demanding surgical, odontologic, phonoaudiologic, and psychological care during childhood and adolescence (1). Their complex etiology in-
Key words

- Homocysteine

- Cleft lip/palate

- Methylenetetrahydrofolate reductase

- Methionine synthase

- Methionine synthase reductase volves genetic and environmental factors (2). Polymorphisms in genes encoding enzymes involved in the metabolism of homocysteine, such as methylenetetrahydrofolate reductase (MTHFR), methionine synthase (MTR) and methionine synthase reductase (MTRR), could play a role in the mechanisms predisposing for clefting.

The metabolism of homocysteine begins with the intake of folic acid through the diet. Folic acid is rapidly reduced to its active form tetrahydrofolate which turns to 5,10- 
methylenetetrahydrofolate. This is then converted into 5-methyltetrahydrofolate by the enzyme methylenetetrahydrofolate reductase, encoded by the MTHFR gene, which has a crucial role in this metabolic pathway (3). This substrate is vital for the metabolism of nucleic acids and amino acids, including those necessary for the synthesis of nucleotides and, consequently, cell division, a fundamental process in development (4). The products of this reaction are methyl groups used for the synthesis of methionine, necessary for DNA methylation (3). In the second step of this metabolic pathway, the enzyme methionine synthase, encoded by the MTR gene, catalyzes the remethylation of homocysteine to methionine, necessary for the production of S-adenosylmethionine, the universal methyl donor. Vitamin $\mathrm{B}_{12}$ acts as a co-factor for methylation (5). Vitamin $\mathrm{B}_{12}$ becomes oxidized over time and the enzyme methionine synthase is inactivated. Functional regeneration of methionine synthase requires the participation of another enzyme, methionine synthase reductase, which is encoded by the MTRR gene $(6,7)$.

Polymorphisms of the genes involved in this metabolic pathway, MTHFR, MTR, and MTRR, can be associated with increased susceptibility to congenital malformations, particularly those related to neural tube defects (8-10). Thus, in the present study, we searched for possible factors involved in susceptibility to clefting disorders related to the metabolism of homocysteine. The frequency of $677 \mathrm{C}>\mathrm{T}$ polymorphism of the MTHFR gene, 2756A $>\mathrm{G}$ of the MTR gene and $66 \mathrm{~A}>\mathrm{G}$ of the MTRR gene was evaluated in children with CL/P and their mothers. Some maternal habits which might interfere with this metabolism during pregnancy were also analyzed.

\section{Subjects and Methods}

The study was approved by the Clinical Hospital of Porto Alegre (HCPA) Ethics
Committee, and the mothers of participating children as well as adults signed an informed consent form. A case-control study was designed. Both cases and controls have a lowsocioeconomic level. The case group included 114 white children aged 0-13 years with non-syndromic CL/P and 110 of their mothers. The control group consisted of 100 white children without malformations, aged $0-13$ years, and their mothers. All cases were recruited at the Cranio-Facial Clinic of HCPA. Controls were invited to participate in the study on the occasion of routine blood withdrawal at the same hospital. Exclusion criteria were mother's refusal to participate or lack of confirmation of non-syndromic CL/P. Case and control samples were collected between January 2004 and June 2005.

Case and control mothers answered a clinical questionnaire with information on patient age and sex, parents' age, consanguinity, other cleft cases in the family, ethnic origin, data about the periconceptional period and pregnancy (including maternal vitamin use and exposure to alcohol and tobacco), and delivery of the child. Mothers who started the use of vitamin supplementation containing folic acid before conception were classified as "users", whereas those who started to use a vitamin supplement at least one month after conception were considered to be "non-users".

The analysis of $677 \mathrm{C}>\mathrm{T}$ polymorphism of the MTHFR gene, 2756A $>\mathrm{G}$ of the MTR gene and $66 \mathrm{~A}>\mathrm{G}$ of the MTRR gene was performed by the polymerase chain reaction (PCR), with previously described specific primers and procedures $(8,7,11)$. The PCRamplified fragments were digested with HinfI, HaeIII and NdeI restriction enzymes, respectively.

The results were analyzed with the EpiInfo software, version 3.3 (2004). The $\chi^{2}$ test was used to determine Hardy-Weinberg ( $\mathrm{H}-$ W) equilibrium and to compare the distribution of allelic frequencies between groups. 


\section{Results}

The characteristics of the groups are presented in Table 1 . The only statistically significant difference observed between the case and control groups was the frequency of first-degree relatives presenting CL/P. Eleven individuals in the case group, but only one in the control group, had a first-degree relative with clefting $(\mathrm{P}<0.01)$. Eight of the case group individuals had affected second-degree relatives and 13 had third-degree relatives with clefting.

Maternal age distribution was analyzed in a total of 110 mothers in the case group and in the 100 control mothers and was found to be similar in the two groups. The potential environmental risk factors investigated are presented in Table 2. Maternal use of vitamin and exposure to alcohol and tobacco, analyzed in 110 mothers of the case group and in 60 of the control mothers, did not differ between groups.

The genotypes and allelic frequencies relative to the polymorphisms studied in the case and control groups are presented in Table 3.

The distribution of MTHFR genotypes did not differ between the two groups and was in $\mathrm{H}-\mathrm{W}$ equilibrium. The frequencies of the $677 \mathrm{~T}$ allelic variant were similar in children with CL/P (0.37), their controls (0.35) and in the mother cases (0.40) and their controls (0.36). The genotype distribution for the MTR gene was in H-W equilibrium and did not show differences between the case and control groups. Frequencies of the $2756 \mathrm{G}$ allele ranged from 0.17 in mothers of the control group to 0.21 in cases, but no statistical difference was observed.

For the MTRR system, however, the genotypic frequencies were not in $\mathrm{H}-\mathrm{W}$ equilibrium in any of the groups (case children: $\chi^{2}{ }_{1}=9.09, \mathrm{P}<0.003$; control children: $\chi^{2}{ }_{1}=$ 9.98, $\mathrm{P}<0.002$; case mothers: $\chi^{2}{ }_{1}=8.02, \mathrm{P}$ $<0.005$; control mothers: $\chi^{2}{ }_{1}=10.16, \mathrm{P}<$ 0.001). Analysis of the A66G mutation for
Table 1. General characteristics of the subjects studied.

\begin{tabular}{lcc}
\hline Characteristics & $\begin{array}{c}\text { Children with clefts } \\
(\mathrm{N}=114)\end{array}$ & $\begin{array}{c}\text { Normal controls } \\
(\mathrm{N}=100)\end{array}$ \\
\hline Gender & $72(63.2 \%)$ & $57(57.0 \%)$ \\
$\quad$ Male & $42(36.8 \%)$ & $43(43.0 \%)$ \\
$\quad$ Female & $4(3.5 \%)$ & $4(4.0 \%)$ \\
Consanguinity & $11(10.0 \%)^{*}$ & $1(1 \%)$ \\
Affected relatives (1st degree) & & - \\
Type of cleft & $87(76.3 \%)$ & - \\
$\quad$ Cleft lip/palate & $27(23.7 \%)$ & $5.9 \pm 3.3$ \\
$\quad$ Cleft palate only & $5.0 \pm 3.8$ & $3385 \pm 383.9$ \\
Age (years, mean \pm SD) & $3152 \pm 624.7$ & \\
Weight at birth (g, mean $\pm \mathrm{SD})$ & &
\end{tabular}

Data are reported as number with percent in parentheses, unless otherwise indicated. ${ }^{*} \mathrm{P}<0.01\left(\chi^{2}{ }_{1}=5.98\right)$.

Table 2. Potential risk factors for cleft lip/palate during pregnancy.

\begin{tabular}{|c|c|c|c|}
\hline Risk factors & Case mothers & Control mothers & Odds ratio $(95 \% \mathrm{Cl})$ \\
\hline \multicolumn{4}{|l|}{ Age at pregnancy } \\
\hline$<18$ years & $17 / 110 \quad(15.4 \%)$ & $12 / 100(12.0 \%)$ & - \\
\hline 19-34 years & $75 / 110 \quad(68.2 \%)$ & 78/100 (78.0\%) & - \\
\hline$>35$ years & $18 / 110 \quad(16.4 \%)$ & 10/100 (10.0\%) & $1.87(0.76-4.69)$ \\
\hline Alcohol & $11 / 110 \quad(10.0 \%)$ & $10 / 60 \quad(16.7 \%)$ & $0.56(0.20-1.53)$ \\
\hline Tobacco & $15 / 110 \quad(13.6 \%)$ & $8 / 60 \quad(13.3 \%)$ & $1.03(0.38-2.85)$ \\
\hline Vitamin supplements & $12 / 110 \quad(10.9 \%)$ & $10 / 60 \quad(16.7 \%)$ & $0.61(0.23-1.66)$ \\
\hline
\end{tabular}

Data are reported as number with percent in parentheses.

Table 3. Distribution of genotypes and allelic frequencies relative to polymorphisms of the MTHFR, MTR and MTRR genes.

\begin{tabular}{lccccc}
\hline & \multicolumn{3}{l}{ Genotypic frequencies } & \multicolumn{2}{c}{ Allelic frequencies } \\
\hline MTHFR 677C>T & $\mathrm{CC}$ & $\mathrm{CT}$ & $\mathrm{TT}$ & $\mathrm{C}$ & $\mathrm{T}$ \\
Case & 49 & 46 & 19 & 0.63 & 0.37 \\
Control & 45 & 41 & 14 & 0.65 & 0.35 \\
Case mother & 44 & 45 & 21 & 0.60 & 0.40 \\
Control mother & 38 & 52 & 10 & 0.64 & 0.36 \\
& & & & & \\
MTR 2756A>G & $\mathrm{AA}$ & $\mathrm{AG}$ & $\mathrm{GG}$ & $\mathrm{A}$ & $\mathrm{G}$ \\
Case & 69 & 42 & 3 & 0.79 & 0.21 \\
Control & 67 & 29 & 4 & 0.81 & 0.19 \\
Case mother & 71 & 36 & 3 & 0.81 & 0.19 \\
Control mother & 70 & 26 & 4 & 0.83 & 0.17 \\
MTRR 66A>G & $\mathrm{AA}$ & $\mathrm{AG}$ & $\mathrm{GG}$ & $\mathrm{A}$ & $\mathrm{G}$ \\
Case & 36 & 69 & 9 & 0.62 & 0.38 \\
Control & 33 & 61 & 6 & 0.64 & 0.36 \\
Case mother & 37 & 65 & 8 & 0.63 & 0.37 \\
Control mother & 35 & 60 & 5 & 0.65 & 0.35 \\
\hline
\end{tabular}

The data were not statistically significant $(P>0.05)$. 
this gene showed a similar genotype distribution between children with CL/P and controls and between their mothers and control mothers. The relative frequencies of the mutant 66G allele in case children (0.38) and their mothers $(0.37)$ were also similar to controls (0.37 and 0.35 , respectively).

\section{Discussion}

Children with orofacial clefts and their mothers were evaluated and compared to normal children and their mothers. Although a higher recurrence level is expected in affected families, in this study we observed a frequency of $10.0 \%$, much higher than the expected value for a multifactorial disease such as $\mathrm{CL} / \mathrm{P}$ which is around 5\% for firstdegree relatives (1). This may be explained by preferential referral of relatives of families already receiving care in the hospital.

The results did not reveal association between alcohol and tobacco use during pregnancy and the occurrence of clefting. These results may be due to the small sample size, since many studies have shown that maternal habits and exposure are possible risk factors for CL/P (12-14). Studies by Talarova and Harris (15) and Itikala et al. (16) have indicated a decreased risk of CL/P among children whose mothers had used vitamin supplementation during pregnancy. We did not observe differences in folic acid supplementation between cases and controls; thus, a possible protective effect of folic acid may have gone undetected since only recently are Brazilian patients becoming aware about the benefits of periconceptional supplementation. It should also be taken into account that we do not have information about the supplementation dosage, nor the specific time period of its use by these women.

In the present study, the $677 \mathrm{~T}$ allele of the MTHFR gene was not associated with the development of CL/P defects in affected children and their mothers. Controversial results have been obtained in the investigation of a possible association between $677 \mathrm{C}>\mathrm{T}$ polymorphism of the MTHFR gene and CL/P. Martinelli et al. (17) reported a role of the 677TT genotype in CL/P risk among white Italian mothers. The results showed a high proportion of the TT genotype in $21 \%$ of the mothers. A Norwegian population-based study (261 case parent-triads) conducted by Jugessur et al. (18), on the other hand, showed that mothers with one or two copies of the 677T allele would present a reduced risk of having children with CL/P. In the same year, Shotelersuk et al. (19) did not detect any association between $109 \mathrm{CL} / \mathrm{P}$ children, 67 of their mothers and 45 fathers, all from Thailand, with allele 677T. Allele frequencies ranged from 0.11-0.17. In a recent case-control study, Pezzetti et al. (20) observed a higher frequency of the $677 \mathrm{~T}$ allele in the mothers of 110 Italian patients with clefts (alelle $\mathrm{T}$ frequency $=0.51)$.

In Latin America, two studies conducted by Gaspar et al. (21) and by Vieira et al. (22) did not find association between the $677 \mathrm{~T}$ allele and clefting, as also observed in our study.

The MTR gene, which codes for the enzyme methionine synthase, is also an interesting target in the study of the metabolism of homocysteine and folic acid. In the present investigation, no association was observed between the $2756 \mathrm{GG}$ risk genotype and the occurrence of CL/P. To our knowledge, this is the first study about the role of the MTR allelic variant in clefting.

The allelic frequency of the MTRR 66G allele in our sample (0.35) was lower than those described in other studies, where frequencies ranging from 0.51 (Brazilian Caucasian population) to 0.55 (European population) of the $66 \mathrm{G}$ allele were reported (23$25)$. This difference may be related to the fact that the population studied in the present investigation was not in $\mathrm{H}-\mathrm{W}$ equilibrium for this polymorphism, suggesting that this population might be susceptible to some type of factor contributing to the modifica- 
tion of these allelic frequencies.

This is the first report of the simultaneous study of polymorphism in three genes involved in the metabolism of folate/homocysteine, MTHFR, MTR, and MTRR, among children with cleft lip/palate and their mothers. It is important to stress the need for future studies of candidate genes coding for enzymes related to the metabolism of folate/ homocysteine, involving polymorphisms other than those found in the MTHFR gene.

\section{Acknowledgments}

We are thankful to all the families that participated in this project. We also thank Dr. Marcus Vinicius Collares of Cranio-Facial Clinic of HCPA for helping with the patients.

\section{References}

1. Murray JC. Gene/environment causes of cleft lip and/or palate. Clin Genet 2002; 61: 248-256.

2. Bender PL. Genetics of cleft lip and palate. J Pediatr Nurs 2000; 15: 242-249.

3. Goyette P, Sumner JS, Milos R, Duncan AM, Rosenblatt DS, Matthews RG, et al. Human methylenetetrahydrofolate reductase: isolation of cDNA, mapping and mutation identification. Nat Genet 1994; 7: 195-200.

4. Bailey LB. New standard for dietary folate intake in pregnant women. Am J Clin Nutr 2000; 71: 1304S-1307S.

5. Leclerc D, Campeau E, Goyette P, Adjalla CE, Christensen B, Ross $\mathrm{M}$, et al. Human methionine synthase: cDNA cloning and identification of mutations in patients of the cblG complementation group of folate/cobalamin disorders. Hum Mol Genet 1996; 5: 1867-1874.

6. Leclerc D, Wilson A, Dumas R, Gafuik C, Song D, Watkins D, et al. Cloning and mapping of a cDNA for methionine synthase reductase, a flavoprotein defective in patients with homocystinuria. Proc Natl Acad Sci USA 1998; 95: 3059-3064.

7. Wilson A, Platt R, Wu Q, Leclerc D, Christensen B, Yang $H$, et al. A common variant in methionine synthase reductase combined with low cobalamin (vitamin B12) increases risk for spina bifida. Mol Genet Metab 1999; 67: 317-323.

8. van der Put NM, van der Molen EF, Kluijtmans LA, Heil SG, Trijbels $\mathrm{JM}$, Eskes TK, et al. Sequence analysis of the coding region of human methionine synthase: relevance to hyperhomocysteinaemia in neural-tube defects and vascular disease. QJM 1997; 90: 511517.

9. Doolin MT, Barbaux S, McDonnell M, Hoess K, Whitehead AS, Mitchell LE. Maternal genetic effects, exerted by genes involved in homocysteine remethylation, influence the risk of spina bifida. Am J Hum Genet 2002; 71: 1222-1226.

10. Sharp L, Little J. Polymorphisms in genes involved in folate metabolism and colorectal neoplasia: a HuGE review. Am J Epidemiol 2004; 159: 423-443.

11. Frosst $P$, Blom HJ, Milos R, Goyette $P$, Sheppard CA, Matthews RG, et al. A candidate genetic risk factor for vascular disease: a common mutation in methylenetetrahydrofolate reductase. Nat Genet 1995; 10: 111-113.

12. Khoury MJ, Weinstein A, Panny S, Holtzman NA, Lindsay PK, Farrel $\mathrm{K}$, et al. Maternal cigarette smoking and oral clefts: a populationbased study. Am J Public Health 1987; 77: 623-625.

13. Wyszynski DF, Duffy DL, Beaty TH. Maternal cigarette smoking and oral clefts: a meta-analysis. Cleft Palate Craniofac J 1997; 34: 206-210.

14. Lieff S, Olshan AF, Werler M, Strauss RP, Smith J, Mitchell A. Maternal cigarette smoking during pregnancy and risk of oral clefts in newborns. Am J Epidemiol 1999; 150: 683-694.

15. Tolarova M, Harris J. Reduced recurrence of orofacial clefts after periconceptional supplementation with high-dose folic acid and multivitamins. Teratology 1995; 51: 71-78.

16. Itikala PR, Watkins ML, Mulinare J, Moore CA, Liu Y. Maternal multivitamin use and orofacial clefts in offspring. Teratology 2001 ; 63: 79-86.

17. Martinelli M, Scapoli L, Pezzetti F, Carinci F, Carinci P, Stabellini G, et al. C677T variant form at the MTHFR gene and CL/P: a risk factor for mothers? Am J Med Genet 2001; 98: 357-360.

18. Jugessur A, Wilcox AJ, Lie RT, Murray JC, Taylor JA, Ulvik A, et al Exploring the effects of methylenetetrahydrofolate reductase gene variants C677T and A1298C on the risk of orofacial clefts in 261 Norwegian case-parent triads. Am J Epidemiol 2003; 157: 10831091.

19. Shotelersuk V, Ittiwut C, Siriwan P, Angspatt A. Maternal 677CT/ 1298AC genotype of the MTHFR gene as a risk factor for cleft lip. $J$ Med Genet 2003; 40: e64.

20. Pezzetti F, Martinelli M, Scapoli L, Carinci F, Palmieri A, Marchesini $\mathrm{J}$, et al. Maternal MTHFR variant forms increase the risk in offspring of isolated nonsyndromic cleft lip with or without cleft palate. Hum Mutat 2004; 24: 104-105.

21. Gaspar DA, Pavanello RC, Zatz M, Passos-Bueno MR, Andre M, Steman S, et al. Role of the C677T polymorphism at the MTHFR gene on risk to nonsyndromic cleft lip with/without cleft palate: results from a case-control study in Brazil. Am J Med Genet 1999; 87: 197-199.

22. Vieira AR, Murray JC, Trembath D, Orioli IM, Castilla EE, Cooper $\mathrm{ME}$, et al. Studies of reduced folate carrier 1 (RFC1) A80G and 5,10methylenetetrahydrofolate reductase (MTHFR) C677T polymorphisms with neural tube and orofacial cleft defects. Am J Med Genet A 2005; 135: 220-223.

23. Rady PL, Szucs S, Grady J, Hudnall SD, Kellner LH, Nitowsky H, et al. Genetic polymorphisms of methylenetetrahydrofolate reductase (MTHFR) and methionine synthase reductase (MTRR) in ethnic populations in Texas; a report of a novel MTHFR polymorphic site, G1793A. Am J Med Genet 2002; 107: 162-168.

24. O'Leary VB, Parle-McDermott A, Molloy AM, Kirke PN, Johnson Z, Conley M, et al. MTRR and MTHFR polymorphism: link to Down syndrome? Am J Med Genet 2002; 107: 151-155.

25. Alessio AC, Annichino-Bizzacchi JM, Bydlowski SP, Eberlin MN, Vellasco AP, Hoehr NF. Polymorphisms in the methylenetetrahydrofolate reductase and methionine synthase reductase genes and homocysteine levels in Brazilian children. Am J Med Genet A 2004; 128: 256-260. 